\title{
Structure and substructure properties of magnesium oxide thin films
}

\author{
O.V. Diachenko, A.S. Opanasuyk, D.I. Kurbatov \\ Dept. of Electronics and Computer Technology \\ Sumy State University \\ Sumy, Ukraine \\ alexey.dyachenko@ukr.net, opanasyuk_sumdu@ukr.net
}

\author{
Ch. Panchal \\ Dept. of Physics \\ The M.S. University of Baroda \\ Gujarat, India
}

\begin{abstract}
In this paper we have conducted a comprehensive study of the structural and substructural characteristics of magnesium oxide films by $\mathrm{X}$-ray diffraction analysis. Thin films MgO were prepared by spray pyrolysis technique from a magnesium chloride solution. Identified the phase composition, the lattice constant, crystallite size and coherent scattering domain size, microstrain level of the films. The optimal conditions for the application of homogeneous single-phase films of stoichiometric composition were identified.
\end{abstract}

Keywords magnesium oxide; spray pyrolysis technique; X-ray diffraction analysis; substructural characteristics; coherent scattering domain size; microstrain.

\section{INTRODUCTION}

Magnesium oxide relates to compounds of $\mathrm{A}_{2} \mathrm{~B}_{6}$ group. It is an insulating material, which has a crystalline structure such as $\mathrm{NaCl}$, characterized by high values of band gap $\left(E_{g}=7.3\right.$ $\mathrm{eV})$, high thermal conductivity and melting temperature (3125 $\mathrm{K})$, and it is stable in a dry atmosphere [1-5].

Magnesium oxide is a promising material for many practical applications. Single-crystal $\mathrm{MgO}$ films are widely used as chemically stable buffer layer for growing hightemperature superconductors and ferroelectric materials [6-9]. Polycrystalline films of this compound are used as a dielectric layer of plasma screens to improve their discharge characteristics and lifetime [2, 10]. Due to the low dielectric loss magnesium oxide is used as a promising material for producing microwave devices andas an insulator, alternative to $\mathrm{SiO}_{2}$, for use in high capacity electrical circuits [3]. In addition, this compound has been applied as a antireflection layer of solar cells and a material of gates of MOSFETs and others [5].

Today, pulsed laser and thermal evaporation, magnetron sputtering cathode and high frequency, chemical vapor deposition, spray pyrolysis, and others are used to obtain magnesium oxide films and nanostructures [1, 11-15]. Recently, much attention has been paid to non-vacuum methods to obtain films of metal oxides, one of which is a spray pyrolysis technique. This method is one of the most promising for film deposition of semiconductors and insulators due to its low cost and ease of equipment, high speed drawing layers and their eligibility for large area substrates of different materials, including flexible.

In most existing works [15-20] the authors have studied $\mathrm{MgO}$ films, deposited by spray pyrolysis technique, using precursors based on magnesium acetate or magnesium acetylacetonate. These works are mainly devoted to the study of their electrical and chemical properties, while dependence of the structural and substructure characteristics of thin layers on the physical and chemical conditions obtaining is poorly investigated. The presented paper describes the results of a comprehensive study of the influence of deposition temperature on the structural and substructure properties of thin films obtained from a magnesium chloride solution.

\section{EXPERIMENTAL DETAILS}

\section{A. Synthesis of $\mathrm{MgO}$ Films}

Magnesium oxide films were obtained on glass substrates $2 \times 2 \mathrm{~cm}^{2}$ by spray pyrolysis technique. Before deposition the substrates surface were cleaned in the tub with ethanol for 5 minutes. Unlike studies [15-20] where layers of $\mathrm{MgO}$ obtained using precursor solutions based on magnesium acetate or magnesium acetylacetonate. We used the $0.2 \mathrm{M}$ magnesium chloride hexahydrate $\left(\mathrm{MgCl}_{2} \cdot 6 \mathrm{H}_{2} \mathrm{O}\right)$ aqueous solution as a precursor solution.

The temperature range of synthesis $\mathrm{MgO}$ films were selected based on a review of published data and experimental studies conducted earlier. In [6], we established in the layers obtained at substrate temperature close to $653 \mathrm{~K}$ only phase magnesium oxide cubic modification was observed. While at the other temperatures we observed a two-phase film containing magnesium hydroxide compound. Therefore, in this paper, the obtaining of the films was carried out at the substrate temperature range of $T_{s}=643 \mathrm{~K}$ to $693 \mathrm{~K}$ with step $\Delta 10 \mathrm{~K}$. For synthesis of thin layers we used the laboratory system described in $[6,21]$.

Substrates temperature during the obtaining of films was measured using a chromel-alumel thermocouple. The distance between the nozzle and the heated substrate surface was equal 
to $12 \mathrm{~cm}$. To transport dispersed precursor particles, the air flow with a pressure of $0.2 \mathrm{MPa}$ was used. Spraying rate was 2 $\mathrm{ml} / \mathrm{min}$ at volume of sprayed solution of $3 \mathrm{ml}$ per sample.

\section{B. Characterization}

M X-ray diffractometer DRON 4-07 in Ni-filtered K $\alpha$ radiation of copper anode $(U=30 \mathrm{kV}, I=20 \mathrm{~mA})$ was used to determine the structural properties. The measurement was carried out in a range of $2 \theta$ angles from $20^{\circ}$ to $80^{\circ}$, where $2 \theta$ is Bragg's angle. The Bragg-Brentano focusing was used for research of $\mathrm{X}$-ray radiation.

The curves were normalized to the peak intensity of the (200) cubic phase of the compound. Phase analysis was performed by comparing interplane distances and relative intensities of the researched samples and the standard according to JCPDS [22].

The texture quality of the films has been estimated by Harris method. Pole density was calculated by the following formula: ${ }_{P}=\frac{\left(I_{i} / I_{0 i}\right)}{1}$, where $I_{i}, I_{0 i}$ are the integrated

$$
P_{i}=\frac{\left(I_{i} / I_{0 i}\right)}{\frac{1}{N} \sum_{i=1}^{N}\left(I_{i} / I_{0 i}\right)}
$$

intensities of the $i$-th diffraction peak for the film sample and standard; $N$ is - the number of lines that are present on the diffraction pattern.

Thereafter $P_{i}-(\mathrm{hkl})_{\mathrm{i}}$ and $P_{i}-\varphi$ dependences were built, where $\varphi$ is the angle between the axis of the texture and perpendicular to different crystallographic planes, which correspond to the reflections in the diffractograms, (hkl) Miller indexes. This angle was calculated for the cubic lattice, using the expressions given in [24]. Texture axis has those indexes, which correspond to the largest value of $P_{i}$.

The orientation factor of the sample can be calculated from the expression: $f=\sqrt{\frac{1}{N} \sum_{i=1}^{N}\left(P_{i}-1\right)^{2}}$.

Calculation of the constants $a$ of the cubic phase of the material was held by the formula: $a=\frac{\lambda}{2 \cdot \sin \theta} \sqrt{\left(h^{2}+k^{2}+l^{2}\right)}$.

The lattice constants were determined using Nelson-Riley extrapolation method [23]. The linear approximation of obtained points was carried out using the method of least squares with the help of OriginPro software package.

The diffractometrical method was also used for estimation of average values of the coherent scattering domain size (CSD) $L$ and microstrain $(\varepsilon)$ by the half-width of the diffraction lines. To separate the diffraction broadening caused by physical and instrumental effects we used approximations of the X-ray line by Cauchy and Gauss functions. Further separation of contributions from dispersion on CSD and microstrain was performed by the graphical method of Williamson-Hall. Accordingly it was built the graphics in coordinates $\beta \cos \theta / \lambda-(4 \sin \theta / \lambda)$ and $(\beta \cos \theta / \lambda)^{2}$ $(4 \sin \theta / \lambda)^{2}$, where $\beta$ is the physical broadening of X-ray line, $\lambda$ - wavelength $X$-rays [20]. Additionally, microstrain and the size of CSD were determined by the method of approximation of the X-ray line as a threefold convolution [23]:

$$
\begin{aligned}
& L=\frac{\lambda}{\cos \theta_{1}} \cdot \frac{t B_{1}-c B_{2}}{t \beta_{f 1}^{2}-\beta_{f 2}^{2}} \\
& \varepsilon^{2}=\frac{c \beta_{f 1}^{2} B_{2}-\beta_{f 2}^{2} B_{1}}{16 \operatorname{tg} \theta_{1}\left(c B_{2}-t B_{1}\right)}
\end{aligned}
$$

where $t=\frac{\operatorname{tg}^{2} \theta_{2}}{\operatorname{tg}^{2} \theta_{1}} ; \quad c=\frac{\cos \theta_{1}}{\cos \theta_{2}} ; \quad \beta_{f i}=\sqrt{\left(B_{i}\right)^{2}-\left(b_{i}\right)^{2}} ; \theta_{l}$ and $\theta_{2}$ are the diffraction angles of the pairs of analyzed lines; and $B_{i}$, $b_{i}, \beta_{f i}$ are the measured, instrumental and physical broadening of the corresponding X-ray lines.

The microstresses level was calculated by the formula $\sigma=$ $E \varepsilon$, where $E$ is the Young's modulus, which equal to $E=90$ $\mathrm{GPa}$ and it was taken from [27].

Further on the basis of calculations of CSD and microstrain we estimated the average dislocation density in the bulk of CSD, on their boundaries, and the total concentration in films. In this case, we used the following equations. The average dislocation density, which forms the boundaries of the blocks, is $\rho_{L}=\frac{3 n}{L^{2}}$ [25], where $n$ is the number of dislocations in each of the six faces of the block. If dislocations are located mainly inside of CSD, the dislocation density is calculated by $\rho_{\varepsilon}=\frac{4}{F}\left(\frac{2 \varepsilon}{d_{0}}\right)^{2}$ [25], where $F$ is a number that takes into account how many times the dislocation energy grows under interaction with other dislocations; and $d_{0}$ is the lattice period of material in the appropriate direction. Taking $n=F=1$, the lower bound for $\rho_{L}$ and the upper bound for $\rho_{\varepsilon}$ can be estimated.

To determine the total concentration of dislocations we used another equation $\rho=\frac{15 \varepsilon}{d_{0} L}$ [23]. These estimations allowed us to calculate the concentration of dislocations, in the bulk of CSD, on their boundaries, and the total concentration.

\section{RESULTS AND DISCUSSION}

Visual inspection showed that the resulting films were optically transparent and uniform.

Fig. 1 shows the diffraction patterns of $\mathrm{MgO}$ films deposited at substrate temperatures from $T_{s}=643$ to $693 \mathrm{~K}$. The analysis showed that all lines corresponding to the cubic phase of $\mathrm{MgO}$. reflection from crystallographic planes of extraneous phases were not observed in the diffraction patterns. It was indicated that in this temperature range, obtained samples were single-phase.

X-ray analysis showed that the dominant intensity has reflections from crystallographic planes of (111) and (200) of cubic phase of magnesium oxide, which indicated about the of growth texture in films. 


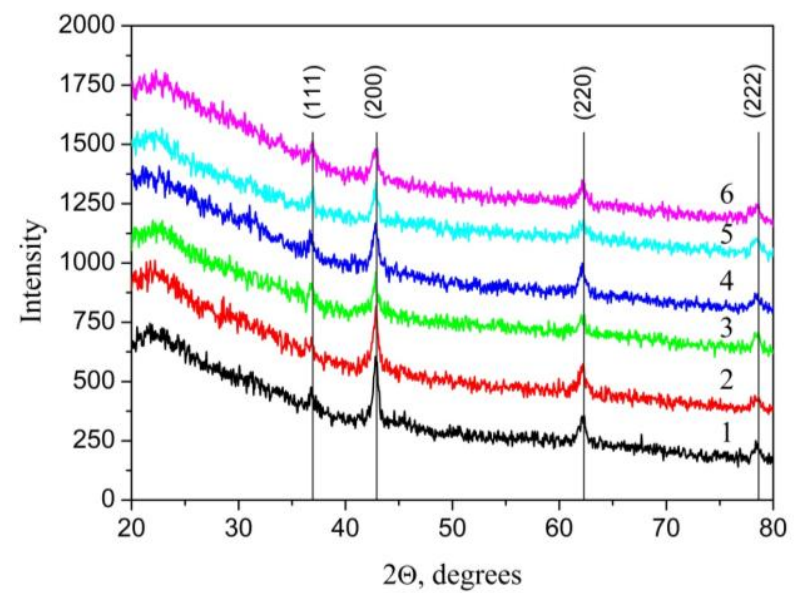

Fig. 1 - XRD patterns of MgO films obtained at $T_{s}, \mathrm{~K}: 643$ (1), 653 (2), 663 (3), 673 (4), 683 (5) та 693 (6)

Calculations of pole density $P_{i}$ and orientation factor $f$ confirmed the precense of pronounced axial texture of growth in $\mathrm{MgO}$ layers [111]. Fig. 2 shows that. The similar growth texture was also observed by the other researchers, in [19, 20, 26].

Fig. 2 (inset) shows the dependences of film's orientation factor on the substrate temperature. As can be seen from the figure, with increasing the substrate temperature, the texture quality also increases.

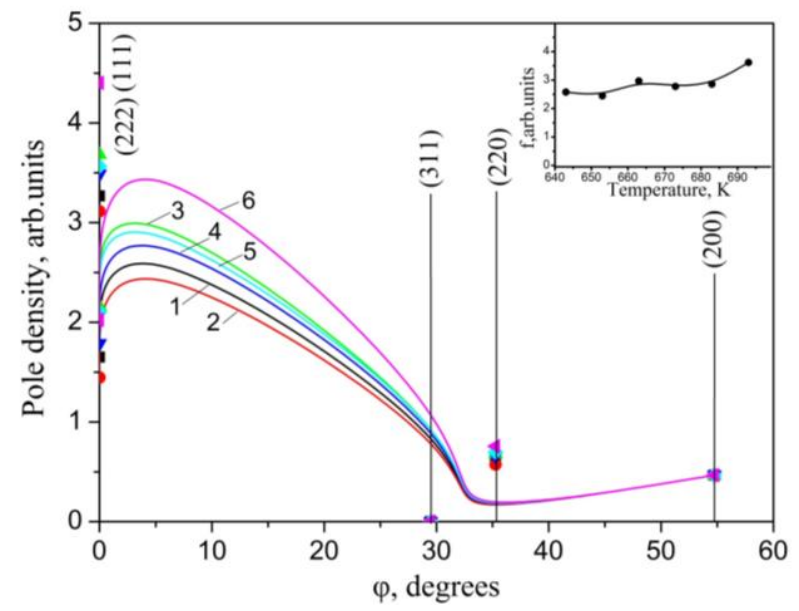

Fig. 2 - Pole density $\left(P_{i}\right)$ as a dependent function of the angle $\varphi$ between the axis of the texture and normal to the reflect-ing plane at temperatures $T_{s}, \mathrm{~K}: 643$ (1), 653 (2), 663 (3), 673 (4), 683 (5) та 693 (6) and orientation factor $(f)$ for films obtained at different substrate temperatures (inset).

The dependence of the lattice constant of $\mathrm{MgO}$ on the substrate temperature during film deposition is presented in Fig. 3. The dotted line in the figure shows the reference values given for this compound [22].

As can be seen from the figure, the lattice constant of $\mathrm{MgO}$ layer that was obtained at $T_{s}=643 \mathrm{~K}$, equal to $a=0,42154$ $\mathrm{nm}$. These values are lower than reference ones.

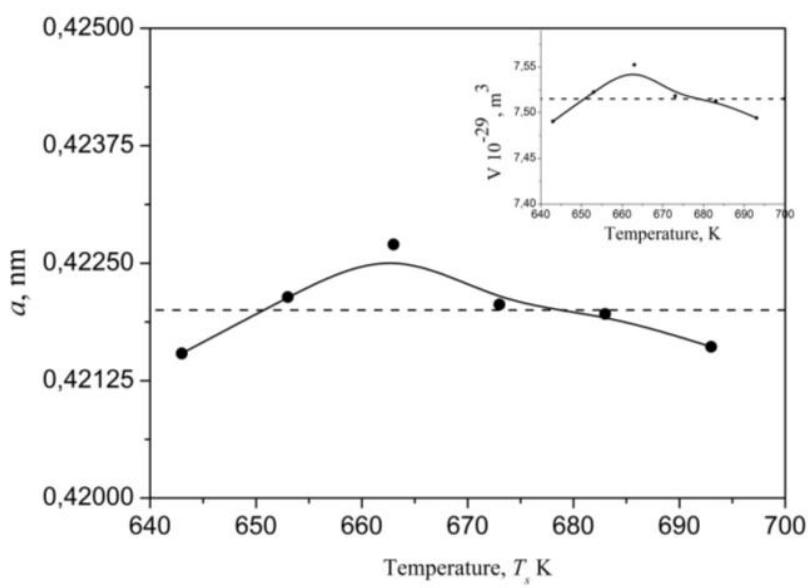

Fig. 3 - Dependence of the lattice constant of $\mathrm{MgO}$ on the substrate temperature and the volume of the primitive cubic cell in obtained $\mathrm{MgO}$ films (inset).

With increasing substrate temperature we observed a gradual increase in the lattice constant of the material $(a=$ $0.42270 \mathrm{~nm}$ at $\left.T_{s}=663 \mathrm{~K}\right)$ to values that exceed the reference one $(a=0.42270 \mathrm{~nm}[22])$. With the further increase $T_{s}$ there took place decrease of lattice parameters of the $\mathrm{MgO}$.

Further on the basis of calculations of lattice constant of the material we calculated the volume of the primitive cubic cell in obtained $\mathrm{MgO}$ films (inset Fig. 3). It was found that increasing the substrate temperature from $T_{s}=643 \mathrm{~K}$ to $T_{s}=$ $663 \mathrm{~K}$ led to increase of the cell volume from $V=74.91 \cdot 10^{30}$ $\mathrm{m}^{-3}$ to $V=75.53 \cdot 10^{30} \mathrm{~m}^{-3}$. With the further increase $T_{s}$ there took place decrease of primitive cubic cell to $V=74.94 \cdot 10^{30}$ $\mathrm{m}^{-3}$ of the MgO. Reference data $V$ are equal to $75.15 \cdot 10^{30} \mathrm{~m}^{-3}$.

Estimations of substructural parameters of obtained films were carried in the direction [111] of crystal lattice of cubic phase (by reflections from the (100) plane and (222) plane). The results of calculations of CSD and microstrain in these crystallographic directions are summarized in Table 1. As it is shown in Table 1, the values of substructural parameters, obtained with the help of different approximations, correlate well with each other, as it should be on theoretical considerations.

TABLE I. SUB-STRUCTURAL FEATURES OF MGO FILMS OBTAINED USING DIFFERENT APPROXIMATIONS

\begin{tabular}{|c|c|c|c|c|c|c|c|}
\hline \multirow{2}{*}{$T$} & \multirow{2}{*}{$T, K$} & $(h k l)$ & \multicolumn{3}{|c|}{$L, \mathrm{~nm}$} & \multicolumn{3}{c|}{$\varepsilon \cdot 10^{3}$} \\
\cline { 3 - 4 } & & \multicolumn{2}{|c|}{$\begin{array}{c}\text { Approximation } \\
\text { by }\end{array}$} & \multirow{2}{*}{$\begin{array}{c}\text { From } \\
\text { convolution }\end{array}$} & \multicolumn{2}{|c|}{$\begin{array}{c}\text { Approximation } \\
\text { by }\end{array}$} & \multirow{2}{*}{$\begin{array}{c}\text { From } \\
\text { convolution }\end{array}$} \\
\cline { 3 - 4 } & & Gauss & Cauchi & Gauss & Cauchi & \\
\hline 643 & $\begin{array}{c}(111)- \\
(222)\end{array}$ & 37.7 & 63.1 & 42.8 & 3.17 & 2.35 & 2.75 \\
\hline 653 & $\begin{array}{c}(111)- \\
(222)\end{array}$ & 20.1 & 49.5 & 27.9 & 2.37 & 1.14 & 1.89 \\
\hline 663 & $\begin{array}{c}(111)- \\
(222)\end{array}$ & 16.1 & 17.8 & 16.2 & 2.56 & 0.91 & 1.91 \\
\hline 673 & $\begin{array}{c}(111)- \\
(222)\end{array}$ & 27.2 & 41.4 & 29.6 & 3.77 & 2.67 & 3.19 \\
\hline 683 & $\begin{array}{c}(111)- \\
(222)\end{array}$ & 32.5 & 65.2 & 40.7 & 4.82 & 3.99 & 4.35 \\
\hline 693 & $\begin{array}{c}(111)- \\
(222)\end{array}$ & 32.5 & 65.2 & 40.7 & 4.82 & 3.99 & 4.35 \\
\hline
\end{tabular}


This demonstrates the reliability of the results. However, the most accurate values were obtained by threefold convolution of the functions.

The dependents of CSD calculation in the direction perpendicular to the crystallographic planes (111) and the microstrain in the same direction on substrate temperature obtained using the threefold convolution are shown in Fig. 4 a.

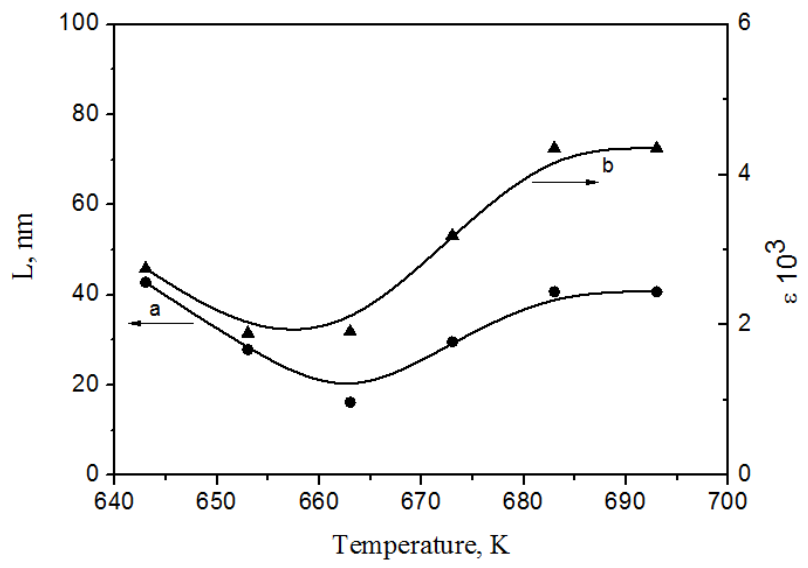

Fig. 4 - Effect of the substrate temperature on (a) CSD $L$ and (b) microstraine obtained using threefold convolution.

It is shown that increasing the synthesis substrate temperature of thin films leads to decrease of CSD from $L \sim$ $43 \mathrm{~nm}$ to $L \sim 16 \mathrm{~nm}$ in the [111] direction and then increase to $L \sim 41 \mathrm{~nm}\left(T_{s}=693 \mathrm{~K}\right)$. The authors of [19] using the Sherrer's ratio obtained similar values of CSD sizes $(L=15$ $\mathrm{nm})$ for magnesium oxide films obtained at temperatures of $673 \mathrm{~K}$ and $723 \mathrm{~K}$ from solutions of magnesium acetylacetonate as precursor. Also, similar results $L=16 \mathrm{~nm}$ were obtained in [16]. These authors synthesized films at temperature range from $T_{s}=673 \mathrm{~K}$ to $873 \mathrm{~K}$ using magnesium acetate as precursor in ethanol with $\mathrm{HCl}$ and TEG.

Fig. 4b shows the dependence of microstrains on synthesis temperature in the studied films. It has a similar in nature to CSD. Firstly The microstrains of thin films decrease from $2.75 \cdot 10^{-3}\left(T_{s}=643 \mathrm{~K}\right)$ to $1.89 \cdot 10^{-3}\left(T_{s}=653 \mathrm{~K}\right)$ and then increase to $4.35 \cdot 10^{-3}\left(T_{s}=693 \mathrm{~K}\right)$.

On the basis of substructure calculations the average dislocation density in the films was estimated (Table 2).

TABLE II. STRUCTURE AND SUBSTRUCTURE PROPERTIES OF MGO THIN FILMS

\begin{tabular}{|c|c|c|c|c|c|c|}
\hline$T, \mathrm{~K}$ & $\begin{array}{c}a, \\
\mathrm{~nm}\end{array}$ & $\begin{array}{c}V \cdot 10^{-29}, \\
\mathrm{~m}^{3}\end{array}$ & $\begin{array}{c}\sigma, \\
\mathrm{MPa}\end{array}$ & $\begin{array}{c}\rho_{L} 10^{-15}, \\
\operatorname{lin} / \mathrm{m}^{2}\end{array}$ & $\begin{array}{c}\rho_{\varepsilon} 10^{-15}, \\
\operatorname{lin} / \mathrm{m}^{2}\end{array}$ & $\begin{array}{c}\rho_{L \varepsilon} 10^{-16}, \\
\operatorname{lin} / \mathrm{m}^{2}\end{array}$ \\
\hline 643 & 0.42154 & 7.491 & 248 & 1.63 & 2.04 & 1.02 \\
\hline 653 & 0.42214 & 7.523 & 386 & 3.85 & 9.47 & 1.07 \\
\hline 663 & 0.42270 & 7.553 & 172 & 1.14 & 9.84 & 1.87 \\
\hline 673 & 0.42206 & 7.518 & 288 & 3.41 & 2.75 & 1.71 \\
\hline 683 & 0.42196 & 7.513 & 392 & 1.81 & 5.09 & 1.70 \\
\hline 693 & 0.42161 & 7.494 & 392 & 1.81 & 5.09 & 1.70 \\
\hline
\end{tabular}

Estimations of microstrain allowed to calculate microstress $(\sigma)$ in the films. It was established that microstress values varied in the range of $\sigma=172-392 \mathrm{MPa}$.

It well known that in II-VI compounds dislocations are effective recombination centers that limit the lifetime of charge carriers. Figure 5 shows the average dislocation density at the boundaries of CSD, in the bulk and the total dislocation density as function of the substrate temperature.

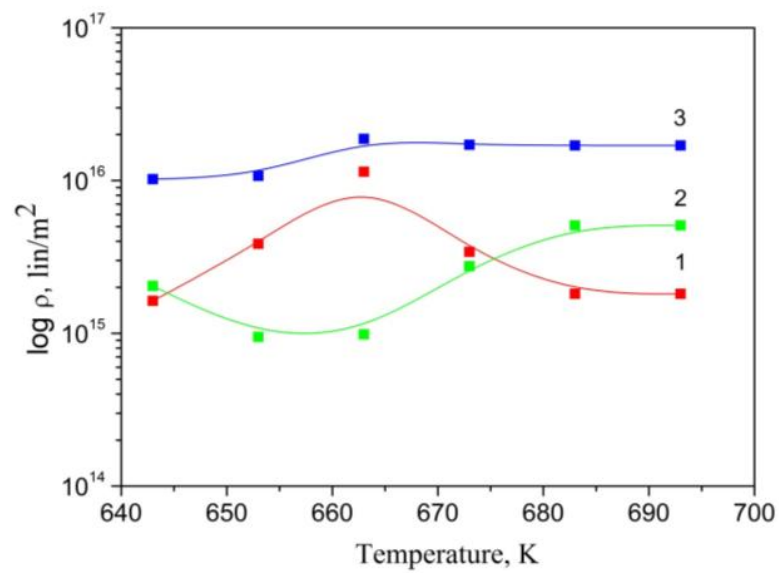

Fig. 5 - Dependence of dislocation density on substrate temperature: (1) dislocations located mainly in the bulk of CSD; (2) dislocations that form the boundaries of the blocks; (3) total concentration of dislocations in the material.

As can be seen from the figure, with increasing substrate temperature we observed some increase the average dislocation density at the boundaries of CSD and then decrease. Whereas the concentration of dislocations on the boundary of CSD slightly increases. As a result, the total dislocation density is almost independent of substrate temperature $\left(\rho_{L \varepsilon}=1.02-1.87 \cdot 10^{-16} \mathrm{lin} / \mathrm{m}^{2}\right)$. Calculations indicate that the dislocations are mainly concentrated on the boundaries of CSD. The bulk of crystallites in the thin films is almost free from dislocations.

\section{CONCLUSIONS}

In this paper we report a comprehensive study of the structural (texture quality and lattice constants) and substructural (coherent scattering domain size, microstrains, and dislocation density) characteristics of nanostructured magnesium oxide films obtained by spray pyrolysis technique from the magnesium chloride hexahydrate at the different substrate temperatures.

It is established, that the obtained films of $\mathrm{MgO}$ were optically transparent and uniform.

X-ray diffractometric researches have allowed us to establish, that $\mathrm{MgO}$ film obtained at the substrate temperature $T_{s}=643-693 \mathrm{~K}$ were single-phase and had cubic structure with a high-quality texture growth of [111], the quality of which depended on $T_{s}$. The values of lattice constant $(a=0.4215$ $0.4227 \mathrm{~nm}$ ) were calculated. It was found the trend to a slight increase of $a$ at the temperature of $T_{s}=643-663 \mathrm{~K}$, with following decreasing of lattice constant at high temperatures. 
It was established that the CSD sizes in $\mathrm{MgO}$ films and microstrains in directions perpendicular to the crystallographic planes of $(111)$ were $L_{(111)}=16.2-42.8 \mathrm{~nm}$ and $\varepsilon \sim(1.89$ $4.35) \cdot 10^{-3}$ respectively.

On the basis of calculations of $\varepsilon$ and $L$, the average density of dislocations located in the bulk $\left(\rho_{\varepsilon}=2.04-9.84 \cdot 10^{15} \mathrm{lin} / \mathrm{m}^{2}\right)$ and on the boundaries of CSD $\left(\rho_{L}=1.14-3.85 \cdot 10^{-15} \mathrm{lin} / \mathrm{m}^{2}\right)$, dislocations, and the total concentration $\left(\rho_{L \varepsilon}=1.02-1.87 \cdot 10^{16}\right.$ $\mathrm{lin} / \mathrm{m}^{2}$ ) of dislocations were estimated.

It is shown that $\mathrm{MgO}$ films with controlled structural properties can be obtained by changing the substrate temperature.

\section{Acknowledgment}

This research was supported by the Ministry of Education and Science of Ukraine (Grant No. 0113U000131, No. 0112U000772).

\section{References}

[1] M. Li, X. Wang, H. Li et al., "Preparation of photoluminescent single crystalline $\mathrm{MgO}$ nanobelts by DC arc plasma jet CVD", Applied Surface Science, vol. 274, pp. 188-194, 2013.

[2] Y.B. Li, Y. Bando, T. Sato, "Preparation of network-like $\mathrm{MgO}$ nanobelts on Si substrate", Chemical Physics Letters, vol. 359, pp.141-145, 2002.

[3] J. Kim, B.P. Gila, R. Mehandru et al., "Electrical characterization of $\mathrm{GaN}$ metal oxide semiconductor diodes using $\mathrm{MgO}$ as the gate oxide, GaN and Related Alloys" in: Proc. Research Society Symposium, vol. 693, pp. 699-713, 2002.

[4] K. Hayashi, S. Matsuishi, T. Kamiya et al., "Light-induced conversionof an insulating refractory oxide into a persistent electronic conductor", Nature, vol. 419, pp.462-465, 2002.

[5] Y. Peidong, C.M. Lieber, "Nanorod-superconductor composites: a pathway to materials with high critical current densities", Science 273, pp.1836-1840, 1996.

[6] A.V. Dyachenko, A.S. Opanasuyk, D.I. Kurbatov et al., "Structural properties of magnesium oxide thin films deposited by spray pyrolysis technique", in: Proc. The International Conference Nanomaterials: Applications And Properties, vol. 3, p. 01001, 2014

[7] W.B. Wang, Y. Yang, A. Yanguas-Gil et al., "Highly conformal magnesium oxide thin films by low temperature chemical vapor deposition from $\mathrm{Mg}(\mathrm{H} 3 \mathrm{BNMe} 2 \mathrm{BH} 3) 2$ and water", Appl. Phys. Lett. 102, 101605, 2013.

[8] S.S.P. Parkin, C. Kaiser, A. Panchula et al., "Giant tunnelling magnetoresistance at room temperature with $\mathrm{MgO}$ (100) tunnel barriers", Nat. Mater., vol. 3, p. 862, 2004

[9] S. Ikeda, K. Miura, H. Yamamoto et al., "A perpendicular-anisotropy $\mathrm{CoFeB}-\mathrm{MgO}$ magnetic tunnel junction", Nat. Mater. vol. 9, p. 721, 2010

[10] E. Fujiia, A. Tomozawaa et al., "Synthesis and characterization of lowmelting and their implementation in MgO", Thin Solid Films, vol. 352, pp. 85-90, 1999 .

[11] J. Senzaki, K. Kurihara et al., "MgO-based coating for electrically insulating semiconductive substrates and production method thereof", J. Appl. Phys. vol. 37, p. 5150, 1998.

[12] M. Nashimoto K. Nashimoto, "Spray pyrolysis deposition and characterization of highly (100) oriented magnesium oxide thin films", J. Appl. Phys. vol. 33, p. L793, 1994

[13] D.K. Fork, F.A. Ponce et al., "Epitaxial $\mathrm{MgO}$ on $\mathrm{Si}(001)$ for $\mathrm{Y}-\mathrm{Ba}-\mathrm{Cu}-$ O thin-film growth by pulsed laser deposition", Appl. Phys. Lett. vol. 58, p. 2294, 1991
[14] S. K. Ram, U. K. Barik, S. Sarkar et al., Thin Solid Films vol. 517, p.6252, 2009 .

[15] O. Stryckmans, T. Segato, P.H. Duvigneaud., "Formation of $\mathrm{MgO}$ films by ultrasonic spray pyrolysis from 13-diketonate", Thin Solid Films vol. 283, p. 17, 1996.

[16] A. Moses Ezhil Raj, L. C. Nehru, M. Jayachandran, C. Sanjeeviraja., "Spray pyrolysis deposition and characterization of highly (100) oriented magnesium oxide thin films", Cryst. Res. Technol. vol. 42, p. 867, 2007.

[17] J. M. Bian, X. M. Li, T. L. Chen et al., "Preparation of high quality $\mathrm{MgO}$ thin films by ultrasonic spray pyrolysis", Applied Surface Science vol.228, p. 297, 2004.

[18] X. Fu, G. Wu, S. Song et al., "Preparation and characterization of $\mathrm{MgO}$ thin films by a simple nebulized spray pyrolysis technique", Applied Surface Science vol. 148, p.223, 1999

[19] X. Yi, W. Wenzhong, Q. Yitai et al., "Deposition and microstructural characterization of $\mathrm{MgO}$ thin films by a spray pyrolysis method", Surface and Coatings Technology vol. 82, p. 291, 1996.

[20] S. G. Kim, J. Y. Kim, H. J. Kim., "Deposition of MgO thin films by modified electrostatic spray pyrolysis method", Thin Solid Films vol. 376 , p. 110,2000

[21] O.A. Dobrozhan, A.S. Opanasyuk, S.B. Bolshanina, "Structural and microstructural properties of $\mathrm{ZnO}$ thin films obtained by spray pyrolysis technique", Odessa polytechnic university proceedings vol. 3, p. 173, 2013.

[22] Selected powder diffraction data for education straining. Search manual and data cards (USA: International Centre for diffraction data: 1997)

[23] M.M. Ivashchenko, D.I. Kurbatov, I.Yu. Protsenko, H. Cheong, "Properties of the Window Layers for the CZTSe and CZTS Based Solar Cells", J. Nano Electron. Phys. vol. 4, pp. 01024-1, 2012.

[24] Ja. S. Umanskij, Crystallogaphy. X-ray graph and electronmicroscopy, Metallurgy. Moskow, 1982.

[25] B.E. Warren, X-ray Diffraction. Dover Books on Physics, New York, 1990.

[26] W.J. De Sisto, R.L. Henry, "Preparation and characterization of $\mathrm{MgO}$ thin films deposited by spray pyrolysis of $\mathrm{Mg}$ ( 2,4-pentanedionate)2", Journal of Crystal Growth vol. 109, p. 314, 1991.

[27] O. Yeheskel, R. Chaim, Z. Shen, M. Nygren, "Elastic moduli of grain boundaries in nanocrystalline $\mathrm{MgO}$ ceramics", J. Mater. Res., vol. 20 (3), pp. 124, 2005. 